SHS Web of Conferences 6, 02012 (2014)

DOI: $10.1051 /$ shsconf / 20140602012

(C) Owned by the authors, published by EDP Sciences, 2014

\title{
The Regulation and Improvement of Suburban Landless Peasants' Community in the Charge of the Government
}

\author{
Zhang Jinsong, Yang Shufang
}

School of Politics and Public Administration, Soochow University, 215123 Suzhou Jiangsu, China

\begin{abstract}
Suburban landless peasants' communities are both the transfiguration in the passive urbanization and transformation in the leading of governments. The specificity of suburban landless peasants community-generated determines the specificity in governing. The deficiency of well governance mechanisms, the scarcity of citizen spirit, the low level of self-organization and the deficiency of social capital in suburban landless peasants' community in the charge of the government bring about a serious of developing dilemma. The regulation and improvement of government should embark on reconstructive governance mechanisms, straighten out organizational system; Cultivating citizen spirit, promoting public participation; Remodeling social capital, tamping autonomy foundation.
\end{abstract}

Keywords. suburban landless peasants' community; Governing; Becoming urban population; Identity dilemmas

Accompanied by urbanization in China spread in full swing, such as the size of cities, the numbers of cities, the number of population are continually extension and expansion, and continue to merge suburban peasants' large tracts of lands which upon production and living, and bring about lots of suburban landless peasants. Most of these suburban landless peasants centered placement of the new community in the outskirts of the city, thus have formed new communities-suburban landless peasants' communities which both different to traditional rural communities and different to general urban communities. As the product of China's industrialization and urbanization, the information of these communities bring about by rapid social change, the meaning have certain uniqueness, the governing in face of more challenges and uniqueness.

\section{The specificity of suburban landless peasants' community in charge of the government}

The suburban landless peasants' communities have formed by some powerful external forces, both the transfiguration in the passive urbanization, also are transformation in the leading of governments. The specificity of suburban landless peasants community-generated determines the specificity in governing.

\subsection{The specificity of governing subject: the villagers convert into urban population}

In the passive process of urbanization, Original country villages scattered replace by populated urban communities, the simplicity of rural life is overwhelmed by the bustling city atmosphere,

This is an Open Access article distributed under the terms of the Creative Commons Attribution License 2.0, which permits unrestricted use, distribution, and reproduction in any medium, provided the original work is properly cited. 
traditional mode of agricultural production replace by non-farm production methods. Thus the suburban landless peasants almost convert to the "citizens" from "villagers". The mandatory process of institutional change which transition from rural to urban areas, can not eliminate the "dual" nature in urban and rural social psychology, can not resolve the role conflict of "villagers" and "citizens". Therefore, suburban landless peasants are hard to complete the adaptation in social role in the short term.

\subsection{The specificity of governing carrier: the village committees transition to neighborhood committees}

The governance carrier of suburban landless peasants' community also transfers from village committee transition to neighborhood committee. But the change not means governance performance optimization. On the one hand, the suburban landless peasants have not yet fully autonomous capability required by the new system due to limited education level. On the other hand, system's moving based on some form, but also reflect specific content, the autonomy system's transition of suburban landless peasants' community is the new institutional arrangements led by government, the transition is faster in the form than in the substance, the neighborhood community have not yet fully play its role in its ought to be level in the specific community governance process.

\subsection{The specificity of governing ecology: rural-oriented urbanization}

Firstly, in the passive process of urbanization, the original social network of suburban peasants' community is dismembered, only a small part was retained, so that the social forms of suburban landless peasants' community have become "social acquaintance" into "semi people in society" and even "stranger society"; Secondly, the development of social economy have Spawned a lot of migrant workers with strong liquidity, due to the high rent of urban communities and the government can not meet their demand for low-cost housing, coupled with the cheap rent, loosely, simple procedures, so the suburban landless peasants'community become the superior choice for them temporarily.

\section{The defects and factors of suburban landless peasants' community in charge of the government}

The current government defects' existing in he suburban landless peasants' community originated from the tradition of social government, also result by the reality of rapid institutional change, with the reason in objective aspect and in subjective aspect.

A. The deficiency of super governance mechanism in suburban landless peasants' community. At the reducing the costs of the institutional change, government ignored convergence of systems' not smooth, which led to the "institutional vacuum" appears. The governance of suburban landless peasants' community lack the necessary institutional guarantee, the collapse of the original system, the existing system not applicable, hard to produce an effective system designed to meet their own reality in short time, which resulted in the institutional level "vacuum" .

B. The scarcity of civism in suburban landless peasants' community.

"Citizen" of landless peasants suburban community level is relatively low, from the countryside to the city's "upheaval" process, the vast majority of people in the more difficult to achieve the lifestyle and values in a short time by a native of the city of a smooth transition, which led to its already very weak citizenship fracture, eventually resulting in a serious shortage of landless peasants suburban community governance of public participation.

$C$. The low "self-organization" level of landless peasants of suburban landless peasants' community.

The indifference of awareness participating in community, "self-organizing" ability of 
community residents will be severely weakened, the serious deficiencies of the organization of community residents to participate in community governance carrier, coupled with the missing of community residents' "subjectivity", eventually accounting for the vast majority of the population in general community residents failed to occupy the dominant position in the community governance, but showed serious" powerlessness "and become the "solitary person" in community governance process. As a result, residents of suburban communities more lack of organization and ability to participate in community governance.

$D$. The lack of social capital in suburban landless peasants' community.

At first, traditional social capital's disintegration in community. Compared to the long-lived rural communities before transfer, the most notable feature of suburban landless peasants' community is the disruption of acquaintances network. The suburban landless peasants are force to be citizens, facing psychological "weak state". Lacking of new community identity and belonging. Second, the missing of newborn social capital, "trust" capital existing in newborn community have been seriously weakened and concentrated expression of the strange relationships based on "hard to trust" and based on resentment of "no confidence". The vulnerability of communities trust structure lead to the establishment of community identity and belonging lags far behind the rapid development of suburban communities of landless peasants.

\section{The regulation and improvement of governance in suburban landless peasants' community}

\subsection{Reconstruction of governance mechanisms in suburban landless peasants' community and rationalize the organizational system}

The construction of the initial system in suburban landless peasants' community, the first is to build governance mechanisms appropriate to their specificity, to form organizational system of governance with government subjects from all parties such as governments, community residents and community organizations responsibilities accurate positioning, function effectively play, clear and smooth relations, thereby forming a stable system to protect the community governance.

The governance of suburban landless peasants' community cannot leave government-led, but the premise is the government can play it well in community governance role ought to accurately locate their own functions, cannot "a head dominance" and can not completely stay out, but must seek the best balance point from "strong embedding" and "totally detached" of executive power poles, and a good grasp of administrative power "degree". As important relying power of grassroots political power, the residents committee should focus on the various tasks of community governance, rather than struggling to cope with a large number of government administrative affairs assessed; should assist local governments to provide public services, to provide convenient conditions for the community improve the service system. Should play a good autonomy function, should be return to "responsible to residents" from "responsible to government", try hard to achieve residents' affairs publicity such as work projects, basis, procedure and responsibilities, and listen modesty to comments and suggestions from resident feedback.

\subsection{Cultivate civic spirit of residents in suburban landless peasants' community, promote public participation}

Suburban landless peasants have experienced a baptism of socialization in "villager autonomy" democratic political life, but the socialization process is adapting to the "social acquaintance" mode of rural life. While the external identity of suburban landless peasants transform "villagers" to "citizens", Their self-identity and values in the original form of "acquaintance society" has not completely disappeared, Most suburban landless peasants' way of thinking and behavior still go on the track of 
rural life in the past, Their consciousness and citizenship have a large gap compared to urban residents. Therefore, in order to adapt to the modern democratic political life of the community, suburban landless peasants have to undergo a process of socialization, from villagers to become citizens in the true sense, in order to fully play their main role in the community governance.

As the leader of suburban landless peasants' community generate, local governments have obligation to support and guide the process of re-socialization suburban community of landless peasants, infiltrate the concept of "become to the citizens" deeply into residents' inside. Thus realize their comprehensive "to be citizens" from the external identity to intrinsic values. Meanwhile, the suburban landless peasants' community can make residents know the importance of participation, establish a sense of ownership of the community by launching various of forms, targeted education activities. Making it clear that their responsibilities in community governance and demonstrates the "subjectivity", thus consciously establish the sense of community participation. And also providing good protection institutionalized for community residents by establishing a sound system of effective participation, and by reducing the cost of participation of residents participating in the program by simplifying, so that community residents can maintain the interest and enthusiasm in community participation, strengthen the sense of community participation.

\subsection{Reshape social capital suburban community of landless peasants, solid foundation of autonomy}

To enhance the sense of identity and belonging of residents living in suburban landless peasants' community. Dilute the sense of loss which produced by losing land in residents of suburban landless peasants' community, change their need of inherent self-identity gradually. "the fact that these landless farmers lost their land to be enlighten and help them recognize the fact that have already losing land, to dispel their dependence to land in their heart" [1]. To help them build a new self-awareness, enhance their self-confidence to adapt to city life; On the other hand, that can be solved by meeting the needs of suburban landless peasants' community service and promoting their employability and income levels. Revamped through a variety of community services (such as health, cleaning, charity, and mutual patrol, etc.) so that the basic needs of the residents in the community would be resolved, thereby enhancing their dependence on the community, enhance their communities sense of identity and belonging; through vocational training to enhance their basic skills and professional skills, try to broaden employment channels and their employment opportunities, encourage and support them to increase revenue through their own businesses, to make their basic survival have a steady economic protection, thus effectively enhance their sense of community. This is the biggest feature of suburban landless peasants' community that not only did the residents to provide high quality public services like the general urban communities, more important is to assume the responsibility of suburban landless peasants' survival and development.

To promote the community integration of migrants in suburban landless peasants' community. In the suburban landless peasants' community, the exchanges between local residents and migrants are mostly based on the relationship between economic leasing, hard to produce trust and establish a stable social relationships due to lack of contacting and communicating each other. Promoting their exchanges and cooperation by mobilizing community residents to participate in community volunteer activities, etc., so as to enhance the maturity phase among community residents, and gradually establish a sense of trust between each other, eventually forming a new "social acquaintance" network, so that formed community residents' home consciousness to community collective. At the same time it's needed to establish a set of fair and equitable criteria which can be recognized and accepted by all members of the community. This mainly includes :improving foreign population management system, doing the registration work while increasing their understanding, caring and helping; optimizing the democratic management system of community, giving migrants the corresponding right to vote and supervise ,preserving their democracy interests, promoting their community involvement; establishing an informal convention communities, a "standard" social capital, allowing foreign population realize self-restraint through modern moral, promoting community trust and reciprocity. 


\section{References}

1. ChunLu and XiDing, The collapse of social acquaintances-the inner transformation of landless peasants and community management strategy, CA: journal of Yunnan Administration Institute, 2010(2) 